Academic Platform Journal of Engineering and Science

\title{
Eğitim Yapılarındaki Dersliklerin Mimari Akustik Açıdan Simülasyon Yöntemi ile Değerlendirilmesi: KTÜ Örneği
}

\author{
${ }^{* 1}$ Mustafa Kavraz, ${ }^{2}$ Öznur Kabil \\ ${ }^{1}$ Karadeniz Teknik Üniversitesi, Mimarlık Fakültesi, Mimarlık Bölümü, 61080, Trabzon, mkavraz@ktu.edu.tr, \\ ${ }^{2}$ Karadeniz Teknik Üniversitesi, Mimarlık Fakültesi, Mimarlık Bölümü, 61080, Trabzon, oznurylz@ hotmail.com \\ Araștırma Makalesi \\ Geliş Tarihi: 18.09.2019 \\ Kabul Tarihi: 04.05.2020
}

Öz

Eğitim yapılarındaki dersliklerde hem eğitimcilerin hem de öğrencilerin sesleri optimum koşullarda algılayabilmeleri büyük önem taşımaktadır. Bu nedenle dersliklerin akustik performansları göz önüne alınarak tasarlanması ve akustik performanslarının denetlenmesi gerekmektedir. Tasarım aşamasındaki akustik denetimler; ya ölçekli fiziksel modeller ya da bilgisayar ortamında sayısal modeller ile gerçekleştirilmektedir. İnşa süreci tamamlanmış olan mevcut mekanların akustik denetimleri ise; ya yerinde yapılan fiziksel ölçüm ya da bilgisayar sayısal modellerin simülasyonu ile gerçekleştirilmektedir. Bu çalışma kapsamında, ODEON version 10 Software kullanılarak Peyzaj Mimarlığı PMD2 No'lu Derslik ile İktisadi ve İdari Bilimler Fakültesi 2-S01 No'lu Dersliğin akustik açıdan denetimi gerçekleştirilmiştir. Öncelikle dersliklerin üç boyutlu sayısal modelleri SketchUp8 programında hazırlanmış, daha sonra modeller ODEON version 10 akustik simülasyon programına aktarılmıştır. Simülasyon işlemi sonucu sesin nesnel parametre değerleri elde edilmiştir. Çalışma kapsamında, öncelikle sesin nesnel parametrelerinden RT, EDT, D $_{50}$ ve STI'ya ait veriler mevcut durum için değerlendirilmiştir. Daha sonra optimum değer aralıklar dişında kalan parametreler, dersliklerin yüzeylerindeki malzeme değişiklikleri ile optimum sınır aralıklarına getirilmiştir.

Anahtar Kelimeler: akustik simülasyon, derslik, tasarım, sesin nesnel parametreleri

\section{Architectural Acoustic Evaluation Of Classrooms Educational Buildings: KTÜ Case}

\author{
${ }^{* 1}$ Mustafa Kavraz, ${ }^{2}$ Öznur Kabil \\ ${ }^{1}$ Karadeniz Teknik Üniversitesi, Mimarlık Fakültesi, Mimarlık Bölümü, 61080, Trabzon, mkavraz@ktu.edu.tr \\ ${ }^{2}$ Karadeniz Teknik Üniversitesi, Mimarlık Fakültesi, Mimarlık Bölümü, 61080, Trabzon, oznurylz@ hotmail.com
}

\begin{abstract}
The perception of sound in optimum conditions in classrooms in educational buildings has great importance for both educators and students. Therefore, classrooms should be designed considering acoustic performance and their acoustic performance should be controlled. Acoustic inspections in the design phase are carried out either by scale physical models or by numerical models in computer environment. The acoustic inspections of the existing spaces, where the construction process has been completed, are carried out either on-site physical measurements or simulation of computer numerical models. Within the scope of this study, the acoustic control of PMD2 Classroom and Class 2-S01 Faculty of Economics and Administrative Sciences was carried out using ODEON version 10 Software. Firstly, 3D numerical models of the classrooms were prepared in SketchUp8 program and then the models were transferred to ODEON version 10 acoustic simulation program. The objective parameter values of the sound were obtained as a result of the simulation process. Within the scope of the study, the data of the objective parameters of sound, RT, EDT, D50 and STI were evaluated for the current situation. Then the parameters outside the optimum value ranges were brought to the optimum ranges by material changes on the surfaces of the classrooms.
\end{abstract}

Keywords: acoustic simulation, classroom, design, objective parameters of sound 


\section{GÍRİş}

İnsanların toplu etkinlikler gerçekleştirdikleri mekanlarda fiziksel konfor koşularının sağlanması, gerçekleştirilen etkinliğin amacına ulaşması açısından önem taşımaktadır. Özellikle çok sayıda insanın birlikte faaliyet gerçekleştirdikleri mekanlarda, mekanın fonksiyonuna da bağlı olarak, sesin katılımcilar tarafindan optimum koşullarda algılanmasının sağlanması fiziksel konfor koşuları açısından tasarımcıların karşısına bir sorun olarak çıkmaktadır. Bu sorunların yaşandığı en önemli mekanlardan biri de eğitim-öğretim faaliyetleri gerçekleştirilen dersliklerdir.

Mekanların akustik tasarımında; biçim, hacim ve yüzeylerde kullanılan malzemeler, dış ortamlardan gelen gürültüye karşı önlem almak için ise; duvar ve döşeme katmanlarında kullanılan malzemeler büyük önem taşımaktadır. Mekanların tasarımlarında sesin yayılımı açısından dikdörtgen tercih edilen bir biçimdir. Derslikler de genellikle dikdörtgen biçim olarak tasarlanmaktadır. İçbükey biçimlerin tercih edildiği durumlarda, sesin odaklanmasını önlemek amacıyla; ya yüzeyin yarıçapının uygun bir şekilde seçilmesi ya da yüzeyleri dağıtıcı olarak tasarlamak gerekmektedir. Derslikler, genellikle doğal sesin düzey olarak iletilmesinde güçlük yaşanmayacak büyüklüklere sahip olduklarından dolayı, genel olarak doğal sesin güçlendirilmesi için büyük mekanlarda gerekli olan özel yansıtıcı yüzeylerin tasarımına bu mekanlarda ihtiyaç duyulmamaktadır. Dikdörtgen mekanlardaki en önemli sorunlardan biri tekrarlayan ekodur. Bununla birlikte, duvarlarda ve tavanda kolon, kiriş, pencere, kap1 gibi girinti çıkıntı oluşturan yüzeyler ile dolap, raf gibi mobilyalar genellikle tekrarlayan ekonun oluşumunu engellemektedirler. Dersliklerde, çınlamanın önlenmesine dikkat etmek gerekmektedir. Bunun için mekan yüzeylerindeki malzeme seçimleri kritik öneme sahiptir. Mekandaki yansitıcılık ve yutuculuk dengelenmesini hacme de bağlı olarak aşağı, orta ve yukarı frekanslarda optimum reverberasyon süresini sağlayacak şekilde gerçekleştirmek, buna bağlı olarak da malzeme seçiminde bulunmak gerekmektedir $[1,2]$.

Mekanlarda akustik koşulların optimum durumda olup olmadığının belirlenmesi; yerinde fiziksel ölçme, sayısal model (bilgisayar simülasyonu) ve ölçekli fiziksel model (maket) yöntemleri ile belirlenebilmektedir. Bilgisayar simülasyon ve maket modelleme yöntemleri, mekanın tasarım aşamasında da uygulanabilen yöntemlerdir. Belirtilen tüm yöntemler, bilimsel çalışmalarda farklı mekanların akustik koşullarının belirlenmesi açısından uygulanmaktadır.

Kavraz (2014) tarafından Trabzon Çarşı Camii için gerçekleştirilen çalışmada, caminin bilgisayar ortamında sayısal modeli oluşturularak akustik özellikleri simülasyon yöntemi ile belirlenmiştir [3]. Eggenschwiler (2006) tarafından yapılan çalışmada, İsviçre Wetzikon şehrinde yer alan Rudolf Steiner School (Waldorf School) binasındaki 12 sınıfın akustik konfor koşulları araştırılmıştır. Araştırmada; arka plan gürültü düzeyi, reverberasyon süresi (RT), ses iletim indeksi (STI) parametreleri ölçülmüş ve genel olarak uygun düzeylerde sonuçlar elde edilmiştir [4]. Awad vd., (2012) tarafından yapılan çalışmada, Mısır'ın İskenderiye kentindeki bir kamu ve iki özel üniversiteye ait eğitim alanlarının akustik performansları değerlendirilmiştir. Her sınıf için ölçülen ses seviyesi, arka plan gürültüsü, sinyalgürültü oranı ve reverberasyon süresi (RT) değerleri Amerika Birleşik Devletleri'ndeki eğitim mekanlarının akustik özellikleri için Amerika Ulusal Standartlar Enstitüsü (ANSI) tarafından geliştirilen kriterler ile karşılaştırılmıştır [5]. Escobar ve Morillas (2015) tarafindan gerçekleştirilen çalışmada, Extremadura Üniversitesi'ndeki (Badajoz, İspanya) 17 oditoryum ve konferans salonunda sesin nesnel parametreleri üzerinden akustik performans değerlendirmeleri yapılmıştır. Değerlendirmeler; ölçülen arka plan gürültü seviyeleri, reverberasyon süreleri (RT), ses iletim indeksleri (STI) nesnel parametreleri için elde edilen sonuçlara göre gerçekleştirilmiştir [6]. Gürel (2007) yapmış olduğu çalışmada, İstanbul Oruçgazi İlköğretim Okulu'nda ölçme (iç mekanda sesin nesnel parametre değerleri) ve anket çalışması aracılığıyla mekanların akustik performans değerlendirmelerini yapmıştır. Çalışmada, seçilen okulun ilköğretim okulları için gerekli olan akustik performans kriterlerinden çoğunu sağladığı sonucuna ulaşmıştır [7]. Özçetin ve diğ. (2015) Bozok Üniversitesi Mimarlık Bölümü'ndeki ölçüm yöntemiyle elde ettikleri verilerle sınıfların akustik açıdan değerlendirmelerini gerçekleştirmişlerdir. Daha sonra, sürdürülebilir malzemelerle iyileştirmeye yönelik önerilerini ise simülasyon yöntemiyle değerlendirmişlerdir. Başlangıçta, havada yayılan sese karşı yalıtımın sağlanamadığı durum yapı malzeme değişiklikleri ile sağlanır duruma getirilmiştir [8]. Karaman ve Üçkaya (2015) Dokuz Eylül Üniversitesi Mimarlık Fakültesi'nde bulunan bir stüdyo ile dersliğe ait sesin nesnel parametre değerlerini ölçme yöntemiyle elde etmişlerdir. Buna ilave olarak, akustik koşulları öznel yöntemlerle de değerlendirmişlerdir. Daha sonra, eldeki veriler doğrultusunda iyileştirme çalışması yapmışlardır. $\mathrm{Bu}$ çalışmanın değerlendirilmesini ise nesnel parametreler aracılığı ile gerçekleştirmişlerdir [9]. Bulunuz ve diğ. (2017) akustik açıdan iyileştirme çalışması yapılan bir okulda, gürültü düzey ölçümleri gerçekleştirmişler ve anket çalışması yapmışlardır. Yapılan iyileştirme çalışmasının anlaşılabilirliği artırdığı ve genel olarak gürültü düzeyini azalttığı sonucuna ulaşmışlardır [10].

$\mathrm{Bu}$ çalışma kapsamında, Karadeniz Teknik Üniversitesi Kanuni Kampüsü'nde yer alan Peyzaj Mimarlığı Bölümü PMD2 No'lu ve İktisadi ve İdari Bilimler Fakültesi 2-SO1 No'lu Dersliklerin akustik özellikleri ODEON version 10 bilgisayar programında belirlenerek mevcut durum için akustik sorunlar ortaya konulmuş ve sonraki süreçte bu sorunlar çözülmüştür.

\section{MALZEME VE YÖNTEM}

Çalışma kapsamında, öncelikle rolöveleri alınan dersliklerin üç boyutlu modelleri SketchUp8 yazılımında hazırlanmıştır. 
Sonraki süreçte, hazırlanan bu modeller simülasyonun gerçekleştirileceği Odeon version 10 programına aktarılmıştır.

Boyu: $6,87 \mathrm{~m}$, eni: $6,50 \mathrm{~m}$, yüksekliği: $3,50 \mathrm{~m}$ ve hacmi: 161 $\mathrm{m}^{3}$ olan Peyzaj Mimarlığı Bölümü PMD2 No'lu Derslik 40 kişi kapasitesinde olup, kişi başına yaklaşık $4 \mathrm{~m}^{3}$ hacim düşmektedir. Formu kare prizmaya yakın olan dersliğin zemini mermer kaplıdır. Duvarların ve tavanın yüzeyleri ise sıva üzerine boya kaplıdır. Dersliğin boyu doğrultusunda; koridor duvarında iki yanda cam sabitleri bulunan ahşap bir kapı ve pano, dış cephe duvarında ise kolonlar arasında pencere yer almaktadır. Eni doğrultusundaki duvarların birinde yazı tahtası, diğerinde ise bir adet pano bulunmaktadır. Şekil 1'de, PMD2 No'lu Dersliğe ait üç boyutlu model yer almaktadır.

Boyu: $8,90 \mathrm{~m}$, eni: 3,55 m, yüksekliği: $3,05 \mathrm{~m}$ ve hacmi: 90 $\mathrm{m}^{3}$ olan İktisadi ve İdari Bilimler Fakültesi 2-S01 No'lu Derslik 28 kişi kapasitesinde olup, derslikte kişi başına yaklaşık $3,21 \mathrm{~m}^{3}$ hacim düşmektedir. Dikdörtgen prizma formundaki dersliğin zemini seramik kaplıdır. Duvarların ve tavanın yüzeyleri sıva üzerine boya kaplıdır. Dersliğin eni doğrultusunda; dış cephe duvarında pencere, koridor duvarında ise üst kısmında cam yer alan bir adet ahşap kapı ve yazı tahtası bulunmaktadır. Şekil 1'de, 2-S01 No'lu Dersliğe ait üç boyutlu model yer almaktadır.

Dersliklerin iç mekan yüzeylerinde kullanılan malzemeler Tablo 1 ve Tablo 3'de yer almaktadır. Optimum değer aralıklarında elde edilemeyen sesin nesnel parametre değerlerinin, optimum aralıklarda elde edilebilmeleri için yapılan iyileştirme çalışmasında değiştirilen malzemeler ise Tablo 2 ve Tablo 4'de gösterilmektedir.

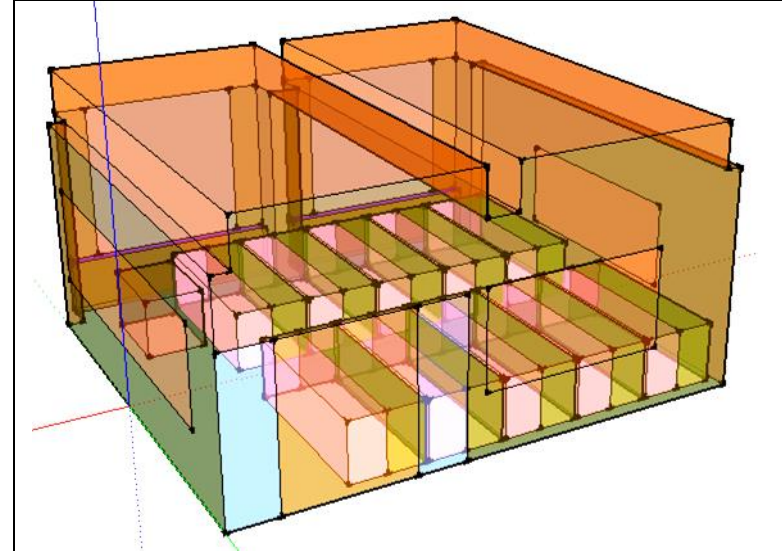

Peyzaj Mimarlığı Bölümü PMD2 No’lu Derslik

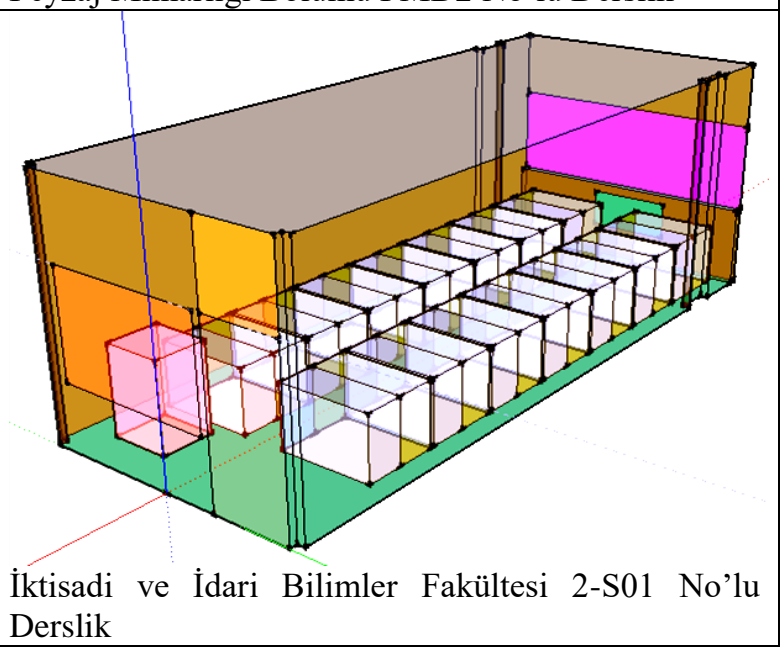

Şekil 1. Dersliklerin ODEON version 10 için hazırlanan modelleri

Tablo 1. Peyzaj Mimarlığı PMD2 No'lu Dersliğinin iç mekan yüzeylerinde kullanılan malzemeler ve 63-8000 Hz oktav bant frekans aralı̆̆ındaki ses yutma katsayıları

\begin{tabular}{|l|l|l|l|l|l|l|l|l|l|l|l|}
\hline NO & Yüzey & $\begin{array}{l}\text { Malzeme } \\
\text { Kodu }\end{array}$ & Malzeme & \multicolumn{6}{|c|}{ Ses yutma Katsayıları } \\
\hline & & & $63 \mathrm{~Hz}$ & $\begin{array}{l}125 \\
\mathrm{~Hz}\end{array}$ & $\begin{array}{l}250 \\
\mathrm{~Hz}\end{array}$ & $\begin{array}{l}500 \\
\mathrm{~Hz}\end{array}$ & $\begin{array}{l}1000 \\
\mathrm{~Hz}\end{array}$ & $\begin{array}{l}2000 \\
\mathrm{~Hz}\end{array}$ & $\begin{array}{l}4000 \\
\mathrm{~Hz}\end{array}$ & $\begin{array}{l}8000 \\
\mathrm{~Hz}\end{array}$ \\
\hline 1 & Tavan & $102^{*}$ & B.A.+Sıva+Boya & 0.01 & 0.01 & 0.01 & 0.01 & 0.02 & 0.02 & 0.02 & 0.02 \\
\hline 2 & Duvarlar & $1001^{*}$ & Tuğla+Sıva+Boya & 0.02 & 0.02 & 0.03 & 0.03 & 0.04 & 0.05 & 0.07 & 0.07 \\
\hline 3 & Dinleyici & $11007^{*}$ & Öğrenci & 0.72 & 0.72 & 0.8 & 0.86 & 0.89 & 0.90 & 0.90 & 0.90 \\
\hline 4 & Pencere & $10003^{*}$ & Çift cam & 0.10 & 0.10 & 0.07 & 0.05 & 0.03 & 0.02 & 0.02 & 0.02 \\
\hline 5 & $\begin{array}{l}\text { Öğrenci } \\
\text { Masası }\end{array}$ & $3004^{*}$ & Ahşap & 0.15 & 0.15 & 0.11 & 0.10 & 0.07 & 0.06 & 0.07 & 0.07 \\
\hline 6 & Kap1 & $10007^{*}$ & Ahşap & 0.14 & 0.14 & 0.1 & 0.06 & 0.08 & 0.10 & 0.10 & 0.10 \\
\hline 7 & Kapı (Cam) & $10001^{*}$ & Tek cam & 0.18 & 0.18 & 0.06 & 0.04 & 0.03 & 0.02 & 0.02 & 0.02 \\
\hline 8 & Yazı Tahtas1 & $14306^{* *}$ & Yansıtıcı yüzey & 0.20 & 0.12 & 0.10 & 0.04 & 0.03 & 0.03 & 0.02 & 0.02 \\
\hline 9 & $\begin{array}{l}\text { Kalorifer } \\
\text { Peteği }\end{array}$ & $5000^{*}$ & Metal & 0.40 & 0.30 & 0.25 & 0.20 & 0.10 & 0.10 & 0.15 & 0.15 \\
\hline 10 & Denizlik & $2001^{*}$ & Mermer & 0.01 & 0.01 & 0.01 & 0.01 & 0.01 & 0.02 & 0.02 & 0.02 \\
\hline 11 & Pano & $14309^{* *}$ & Açı̈k örgü kumaş & 0.35 & 0.35 & 0.7 & 0.90 & 0.90 & 0.95 & 0.90 & 0.90 \\
\hline 12 & $\begin{array}{l}\text { Zemin } \\
\text { Döşemesi }\end{array}$ & $2001^{*}$ & Mermer & 0.01 & 0.01 & 0.01 & 0.01 & 0.01 & 0.02 & 0.02 & 0.02 \\
\hline
\end{tabular}


Tablo 2. Peyzaj Mimarlığı PMD2 No'lu Dersliğin iyileştirme çalışması için değiştirilen malzemeler ve 63-8000 Hz oktav bant frekans aralığındaki ses yutma katsayıları

\begin{tabular}{|l|l|l|l|c|c|c|c|c|c|c|c|}
\hline \multirow{2}{*}{ NO } & \multirow{2}{*}{ Yüzey } & \multirow{2}{*}{$\begin{array}{l}\text { Malzeme } \\
\text { Kodu }\end{array}$} & Malzeme & \multicolumn{8}{|c|}{ Ses yutma Katsayıları } \\
\cline { 5 - 12 } & & $\begin{array}{c}63 \\
\mathrm{~Hz}\end{array}$ & $\begin{array}{c}125 \\
\mathrm{~Hz}\end{array}$ & $\begin{array}{c}250 \\
\mathrm{~Hz}\end{array}$ & $\begin{array}{c}500 \\
\mathrm{~Hz}\end{array}$ & $\begin{array}{c}1000 \\
\mathrm{~Hz}\end{array}$ & $\begin{array}{c}2000 \\
\mathrm{~Hz}\end{array}$ & $\begin{array}{c}4000 \\
\mathrm{~Hz}\end{array}$ & $\begin{array}{c}8000 \\
\mathrm{~Hz}\end{array}$ \\
\hline 1 & Tavan & 14302 & $\begin{array}{l}\text { Taş yünü karo } \\
\text { levha }\end{array}$ & 0.28 & 0.29 & 0.33 & 0.53 & 0.73 & 0.86 & 0.92 & 0.92 \\
\hline 2 & Duvarlar & 7001 & Alçı sıva & 0.03 & 0.03 & 0.09 & 0.25 & 0.31 & 0.33 & 0.44 & 0.44 \\
\hline 12 & Zemin & 7004 & Halı & 0.02 & 0.02 & 0.06 & 0.14 & 0.37 & 0.6 & 0.65 & 0.65 \\
\hline 13 & $\begin{array}{l}\text { Ön, Arka ve } \\
\text { Yan Duvarlar }\end{array}$ & 4045 & Alçı̨pan panel & 0.28 & 0.28 & 0.12 & 0.10 & 0.17 & 0.13 & 0.09 & 0.09 \\
\hline 14 & $\begin{array}{l}\text { Aydınlatma } \\
\text { Elemanı }\end{array}$ & 14306 & $\begin{array}{l}\text { Siva altı } \\
\text { aydınlatma } \\
\text { armatürü }\end{array}$ & 0.2 & 0.12 & 0.10 & 0.04 & 0.03 & 0.03 & 0.02 & 0.02 \\
\hline
\end{tabular}

Tablo 3. İktisadi ve İdari Bilimler Fakültesi 2-S01 No’lu Dersliğinin iç mekan yüzeylerinde kullanılan malzemeler ve $63-8000 \mathrm{~Hz}$ oktav bant frekans aralığındaki ses yutma katsayıları

\begin{tabular}{|c|c|c|c|c|c|c|c|c|c|c|c|}
\hline \multirow[b]{2}{*}{ NO } & \multirow[b]{2}{*}{ Yüzey } & \multirow[b]{2}{*}{$\begin{array}{l}\text { Malzeme } \\
\text { Kodu }\end{array}$} & \multirow[b]{2}{*}{ Malzeme } & \multicolumn{8}{|c|}{ Ses yutma Katsayıları } \\
\hline & & & & $\begin{array}{l}63 \\
\mathrm{~Hz}\end{array}$ & $\begin{array}{l}125 \\
\mathrm{~Hz}\end{array}$ & $\begin{array}{l}250 \\
\mathrm{~Hz}\end{array}$ & $\begin{array}{l}500 \\
\mathrm{~Hz}\end{array}$ & $\begin{array}{l}1000 \\
\mathrm{~Hz}\end{array}$ & $\begin{array}{l}2000 \\
\mathrm{~Hz}\end{array}$ & $\begin{array}{l}4000 \\
\mathrm{~Hz}\end{array}$ & $\begin{array}{l}8000 \\
\mathrm{~Hz}\end{array}$ \\
\hline 1 & Pencere & $10001^{*}$ & Tek cam & 0.18 & 0.18 & 0.06 & 0.04 & 0.03 & 0.02 & 0.02 & 0.02 \\
\hline 2 & Yazı Tahtas1 & $3004^{*}$ & Ahşap & 0.15 & 0.15 & 0.11 & 0.10 & 0.07 & 0.06 & 0.07 & 0.07 \\
\hline 3 & Kürsü & $3004^{*}$ & Ahşap & 0.15 & 0.15 & 0.11 & 0.10 & 0.07 & 0.06 & 0.07 & 0.07 \\
\hline 4 & Dinleyici & $11007^{*}$ & Öğrenci & 0.72 & 0.72 & 0.8 & 0.86 & 0.89 & 0.90 & 0.90 & 0.90 \\
\hline 5 & Tavan & $102^{*}$ & BA+Siva+Boya & 0.01 & 0.01 & 0.01 & 0.01 & 0.02 & 0.02 & 0.02 & 0.02 \\
\hline 6 & Öğrenci Masas1 & $3004^{*}$ & Ahșap & 0.15 & 0.15 & 0.11 & 0.10 & 0.07 & 0.06 & 0.07 & 0.07 \\
\hline 7 & Denizlik & $2001^{*}$ & Mermer & 0.01 & 0.01 & 0.01 & 0.01 & 0.01 & 0.02 & 0.02 & 0.02 \\
\hline 8 & Kap1 1 & $10007^{*}$ & Ahşap & 0.14 & 0.14 & 0.10 & 0.06 & 0.08 & 0.10 & 0.10 & 0.10 \\
\hline 9 & Kap1 2 & $10002^{*}$ & $3 \mathrm{~mm}$ cam & 0.08 & 0.08 & 0.04 & 0.03 & 0.03 & 0.02 & 0.02 & 0.02 \\
\hline 10 & Kalorifer Peteği & $5000^{*}$ & Metal & 0.40 & 0.30 & 0.25 & 0.20 & 0.10 & 0.10 & 0.15 & 0.15 \\
\hline 11 & Duvarlar & $1001^{*}$ & Tuğla+Siva & 0.02 & 0.02 & 0.03 & 0.03 & 0.04 & 0.05 & 0.07 & 0.07 \\
\hline 12 & Zemin Döșemesi & $14307^{* *}$ & Seramik & 0.01 & 0.01 & 0.01 & 0.01 & 0.02 & 0.02 & 0.02 & 0.02 \\
\hline
\end{tabular}

Tablo 4. İktisadi ve İdari Bilimler Fakültesi 2-S01 No’lu Dersliğin iyileştirme çalışması için değiştirilen malzemeler ve $63-8000 \mathrm{~Hz}$ oktav bant frekans aralığındaki ses yutma katsayıları

\begin{tabular}{|c|c|c|c|c|c|c|c|c|c|c|c|}
\hline \multirow[b]{2}{*}{ NO } & \multirow[b]{2}{*}{ Yüzey } & \multirow[b]{2}{*}{$\begin{array}{l}\text { Malzeme } \\
\text { Kodu }\end{array}$} & \multirow[b]{2}{*}{ Malzeme } & \multicolumn{8}{|c|}{ Ses yutma Katsayıları } \\
\hline & & & & $\begin{array}{l}63 \\
\mathrm{~Hz}\end{array}$ & $\begin{array}{l}125 \\
\mathrm{~Hz}\end{array}$ & $\begin{array}{l}250 \\
\mathrm{~Hz}\end{array}$ & $\begin{array}{l}500 \\
\mathrm{~Hz}\end{array}$ & $\begin{array}{l}1000 \\
\mathrm{~Hz}\end{array}$ & $\begin{array}{l}2000 \\
\mathrm{~Hz}\end{array}$ & $\begin{array}{l}4000 \\
\mathrm{~Hz}\end{array}$ & $8000 \mathrm{~Hz}$ \\
\hline 5 & Tavan & 14302 & $\begin{array}{l}\text { Taş yünü } \\
\text { karo levha }\end{array}$ & 0.28 & 0.29 & 0.33 & 0.53 & 0.73 & 0.86 & 0.92 & 0.92 \\
\hline 11 & Duvarlar & 7001 & Alçı sıva & 0.03 & 0.03 & 0.09 & 0.25 & 0.31 & 0.33 & 0.44 & 0.44 \\
\hline 12 & $\begin{array}{l}\text { Zemin } \\
\text { Döşemesi }\end{array}$ & 7004 & Halı & 0.02 & 0.02 & 0.06 & 0.14 & 0.37 & 0.6 & 0.65 & 0.65 \\
\hline 13 & $\begin{array}{l}\text { Aydınlatma } \\
\text { Elemanı }\end{array}$ & 14306 & $\begin{array}{l}\text { Siva alt1 } \\
\text { aydınlatma } \\
\text { armatürü }\end{array}$ & 0.20 & 0.12 & 0.10 & 0.04 & 0.03 & 0.03 & 0.02 & 0.02 \\
\hline 14 & Sol Yan Duvar & 3004 & Ahşap & 0.15 & 0.15 & 0.11 & 0.1 & 0.07 & 0.06 & 0.07 & 0.07 \\
\hline
\end{tabular}

* : Odeon V10 programımın kütüphanesinden seçilen malzemedir [11].

**: [12]

Simülasyon sürecinde, öncelikle SketchUp8'de hazırlanan üç boyutlu modeller Odeon version 10 simülasyon programına aktarılmış ve denetim süreci başlatılmıştır. Odeon version 10'da modellerin yüzeylerine genel malzeme atamaları yapılarak yüzeylerin birleşim hatalarının denetimi gerçekleştirilmiş ve sorunlu birleşimler yeniden düzenlenmiştir. Daha sonra, modellerin yüzeylerine malzeme atamaları gerçekleştirilmiştir. Programda yer alan hesap parametrelerine ait değerlerin atamalarının yapılmasından sonra, program koşturularak sesin nesnel parametrelerine ait değerler elde edilmiştir [13]. Programda ses kaynakları ve alıcıların konumlarının atama işlemleri de gerçekleştirilmiştir. Ses kaynakları, aks eksenleri üzerinde konumlandırılmış ve zemin kotlarından $1.50 \mathrm{~m}$. yüksekliğe yerleştirilmiştir. Alıcılar ise, plan düzlemlerinde 0.50x0.50 $\mathrm{m}$. gridler olarak tanımlanmışlar ve zeminden $1.20 \mathrm{~m}$. üst kota yerleştirilmişlerdir (Şekil 2). 


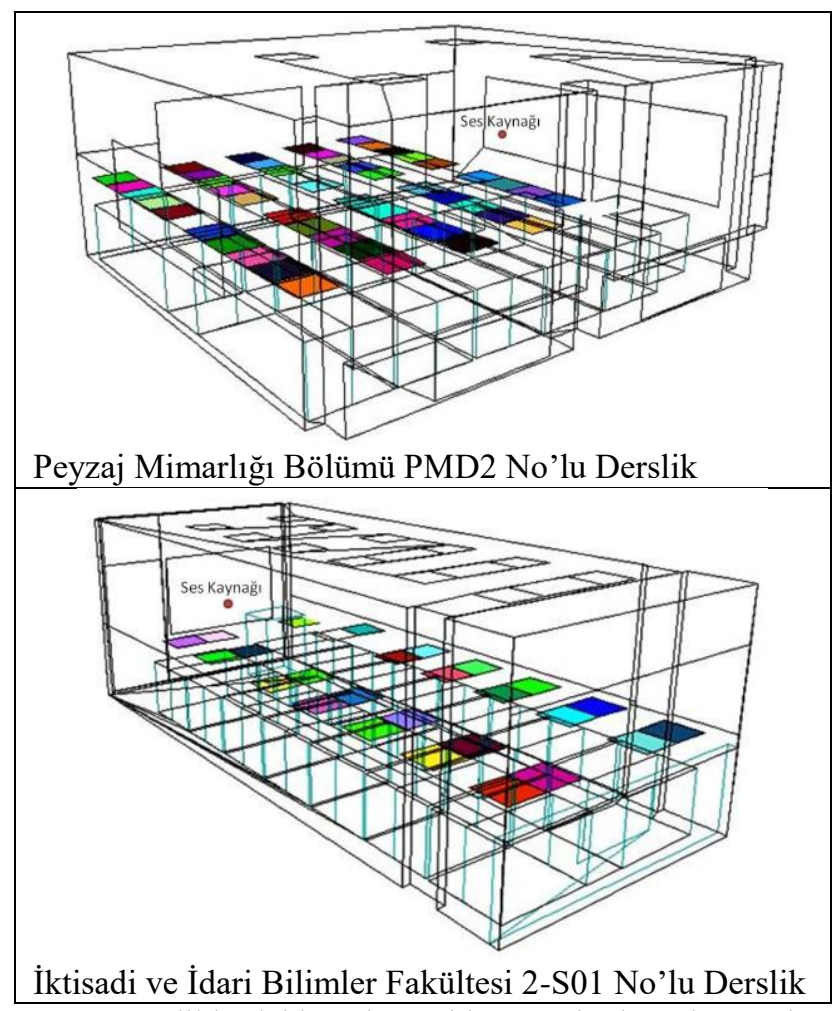

\section{BULGULAR VE DEĞERLENDİRME}

Odeon version 10 ile yapılan simülasyon işlemleri sonucunda elde edilen sesin nesnel parametre değerleri, öncelikle dersliklerin hacimlerine de bağlı olarak elde edilen optimum değer aralıkları ile karşılaştırılmıştır. Daha sonra, optimum değer aralıkları dışındaki değerlerin optimum aralıklarda elde edilebilmeleri için dersliklerin yüzeylerinde malzeme değişiklikleri yapılmıştır.

3.1. Peyzaj Mimarlığı PMD2 No'lu Dersliğin Mevcut Durumu için Elde Edilen Sesin Nesnel Parametrelerinin Değerlendirilmesi

Peyzaj Mimarlığı PMD2 No'lu Dersliğin akustik konfor koşullarının incelenmesi için kullanılan sesin nesnel parametrelerine ait optimum değer aralıkları, mekanın mevcut durumu ve iyileştirme çalışması doğrultusunda yapılan malzeme değişikliklerinden sonraki durumu için Tablo 5'de verilmiştir.

Şekil 2. Dersliklerdeki ses kaynakları ve alıcıların konumları

Tablo 5. Peyzaj Mimarlığı PMD2 No’lu Dersliğin mevcut ve malzeme değişikliğinden sonraki durumu için sesin nesnel parametrelerine ait optimum değer aralıkları [14], [15], [16], [17], [18]

\begin{tabular}{|c|c|c|c|c|c|c|}
\hline $\begin{array}{l}\text { Hacim Akustiği } \\
\text { Parametresi }\end{array}$ & $\begin{array}{l}\text { Peyzaj Mimarlığı PMD2 } \\
\text { No'lu Derslik }\end{array}$ & \multicolumn{3}{|c|}{ Optimum (minimum) } & \multicolumn{2}{|c|}{ Optimum (maksimum) } \\
\hline \multirow{2}{*}{$\mathrm{RT}$} & Mevcut & \multicolumn{3}{|l|}{0,35} & \multicolumn{2}{|l|}{0,55} \\
\hline & Malzeme değişikliği & \multicolumn{3}{|l|}{0,32} & \multicolumn{2}{|l|}{0,52} \\
\hline \multirow{2}{*}{$\mathrm{EDT}_{\text {mid }}$} & Mevcut & \multicolumn{3}{|l|}{0,185} & \multicolumn{2}{|l|}{0,405} \\
\hline & Malzeme değişikliği & \multicolumn{3}{|l|}{0,152} & \multicolumn{2}{|l|}{0,372} \\
\hline $\mathrm{D}_{50}$ & Her iki durum için & \multicolumn{5}{|l|}{$0,50 \leq$} \\
\hline \multirow[b]{2}{*}{ STI } & \multirow{2}{*}{ Her iki durum için } & $0-0.3$ & $0.3-0.45$ & $0.45-0.6$ & $0.6-0.75$ & $0.75-1.0$ \\
\hline & & Kötü & Zayıf & Orta & İyi & Mükemmel \\
\hline
\end{tabular}

3.1.1. Reverberasyon Süresi (RT): Dersliğin mevcut durumu için RT değeri 500 Hz'de (orta frekans bölgesi) 0,77 sn. olarak elde edilmiştir (Şekil 3). Küçük hacimli mekan kapsamında incelenen ve $163 \mathrm{~m}^{3}$ hacme sahip olan dersliğin, orta frekans bölgesindeki optimum RT değeri 0,35 ile $0,55 \mathrm{sn}$. aralığındadır (Tablo 5). Belirtilen değer aralıklarına göre, RT değeri optimum düzeyin üzerinde elde edilmiştir.

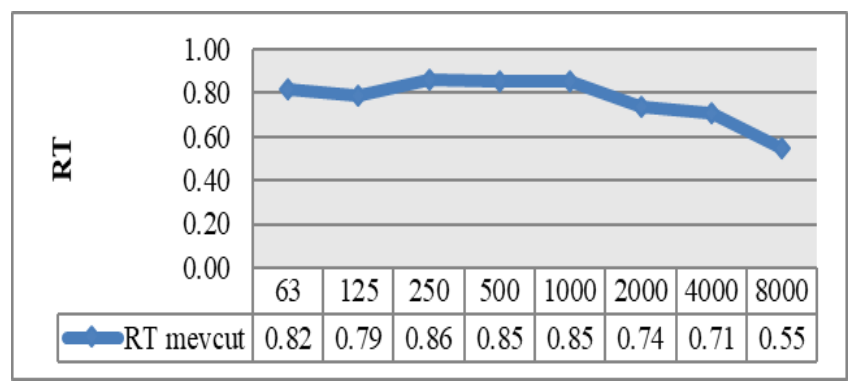

Şekil 3. Oktav band frekanslarda elde edilen RT değerleri 
3.1.2. Erken Düşme Süresi (EDT): Dersliğin mevcut durumu için EDT değeri, $500 \mathrm{~Hz}$ 'de (orta frekans bölgesi) 0,91 sn. olarak elde edilmiştir (Şekil 4). Optimum EDT değeri ise, orta frekans bölgesinde 0,185 ile 0,405 sn. aralığındadır (Tablo 5). Belirtilen değer aralığına göre, dersliğin mevcut durumu için EDT değeri optimum düzeyin üzerinde elde edilmiştir.

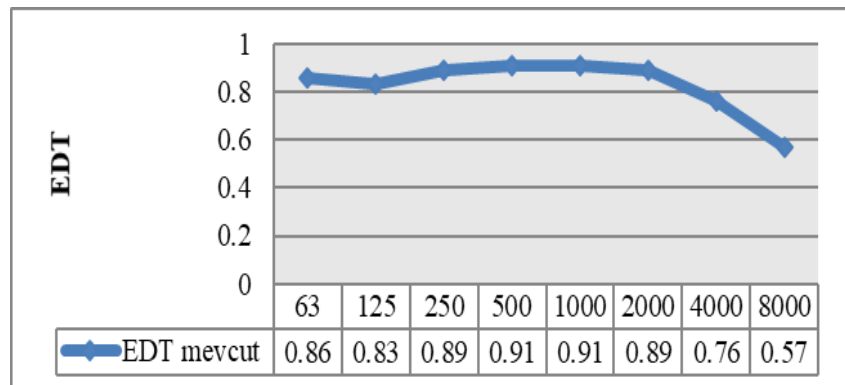

Şekil 4. Oktav band frekanslarda elde edilen EDT değerleri

3.1.3. Konuşmanın Belirginliği (D50): Dersliğin mevcut durumu için $\mathrm{D}_{50}$ değeri 0,53 olarak elde edilmiştir (Şekil 5). $\mathrm{Bu}$ değer $\mathrm{D}_{50}$ optimum alt sinır değerinin üzerindedir. Dersliğin mevcut durumu için \%50'nin üzerinde olan $\mathrm{D}_{50}$ parametresine göre, konuşmanın belirginliğinin yeterli düzeyde olduğu belirlenmiştir.

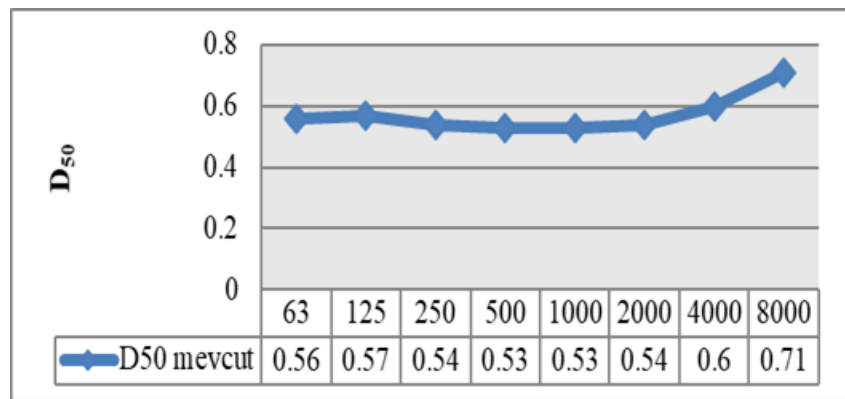

Şekil 5. Oktav band frekanslarda elde edilen $\mathrm{D}_{50}$ değerleri

3.1.4. Ses İletim İndeksi (STI): Dersliğin mevcut durumu için STI değeri 0,63 olarak elde edilmiştir (Şekil 6). Elde edilen STI, anlaş1labilirliğin iyi düzeyde olduğu 0,60 ile 0,75 değer aralığındadır (Tablo 5).

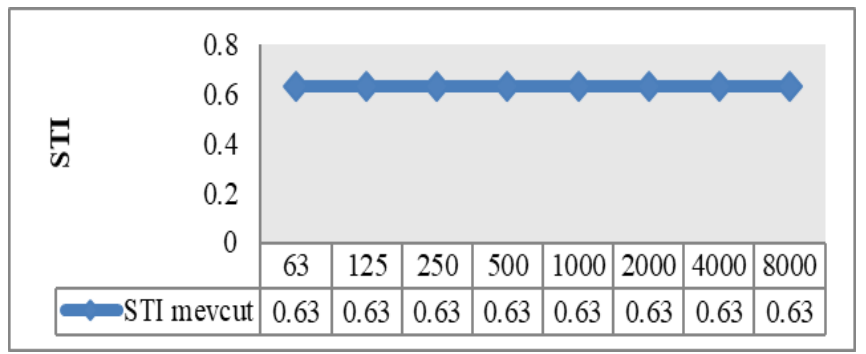

Şekil 6. Oktav band frekanslarda elde edilen STI değerleri

\subsection{Peyzaj Mimarlığı PMD2 No'lu Derslik için İyileștirme Calıșması}

Peyzaj Mimarlığı PMD2 No'lu Derslik için elde edilen RT ve EDT değerlerini optimum düzeylere, $D_{50}$ ve STI değerlerini daha iyi düzeylere getirmek amaciyla mekan yüzeylerinde bazı malzeme değişiklikleri yapılmıştır. Malzeme değişikliğinde, döşemede: alçak frekanslardan yüksek frekanslara doğru ses yutuculukları giderek artış gösteren halı kaplama, tavanda: taş yünü karo levhalar, duvarlarda: alçı sıva kullanılmıştır. Arka ve yan duvarlarda: yerden başlayarak $90 \mathrm{~cm}$ yukarıya kadar alçıpan paneller kullanılmıştır. Tavanda kullanılan taş yünü asma tavan uygulaması ile uyumlu şekilde, sıva altı aydınlatma armatürleri kullanılmıştır (Tablo 2). İyileştirme çalışması kapsamında, PMD2 No'lu Dersliğin Sketchup 8 programı ile yeniden modellemesi yapılmış ve ODEON v10 programında simülasyon işlemi gerçekleştirilmiştir. Elde edilen sesin nesnel parametre değerlerine göre sonuçlar tekrar değerlendirilmiştir.

3.2.1. Reverberasyon Süresi (RT): Malzeme değişiklikleri ile meydana gelen tavan formundaki değişiklik sonucunda mekanın hacmi $127 \mathrm{~m}^{3}$ 'e düşmüştür. Bu hacme sahip bir mekandaki optimum RT değer aralığ 0,32 ile 0,52 sn.'dir (Tablo 5). Bu değer aralığına göre, malzeme değişiklikleri sonrasında RT değeri 0,38 sn. ile optimum düzeyde elde edilmiştir (Şekil 7).

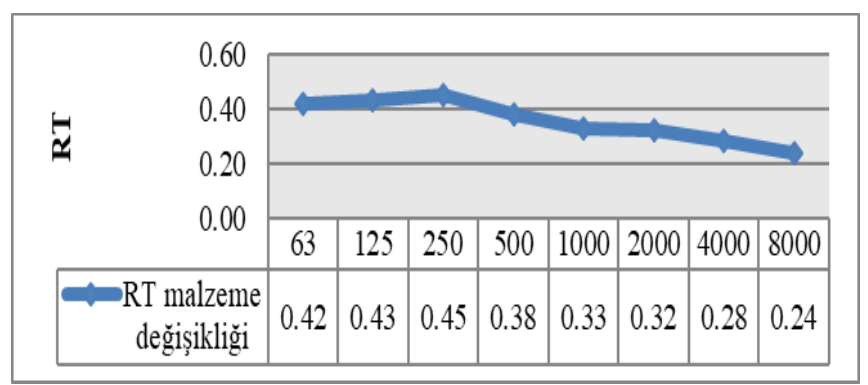

Şekil 7. Oktav band frekanslarda elde edilen RT değerleri

3.2.2.Erken Düşme Süresi (EDT): Derslik için malzeme değişikliklerinden sonraki optimum EDT değeri 0,152 ile 0,372 sn. aralığındadır (Tablo 5). Dersliğin mevcut durumu için optimum değer aralığında olmayan EDT değeri $(0,91$ sn.), malzeme değişikliğinden sonra 0,35 sn. ile optimum düzeyde elde edilmiştir (Şekil 8).

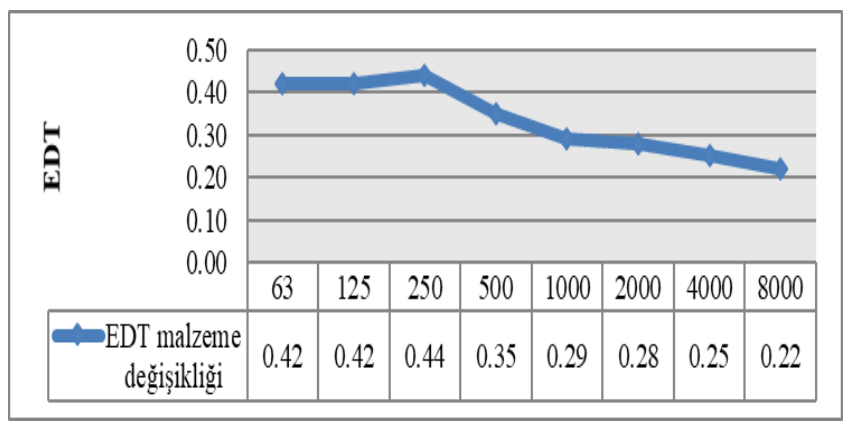

Şekil 8. Oktav band frekanslarda elde edilen EDT değerleri

3.2.3. Konuşmanın Belirginliği (D50): Malzeme değişikliklerinden sonra elde edilen $\mathrm{D}_{50}$ değerinde $(0,88)$, mevcut durumdaki $\mathrm{D}_{50}$ değerine $(0,53)$ göre artış meydana gelmiştir (Şekil 9). Değişiklik sonrasında, derslik için konuşmanın belirginliğinin mevcut duruma göre çok daha iyi olduğu belirlenmiştir. 


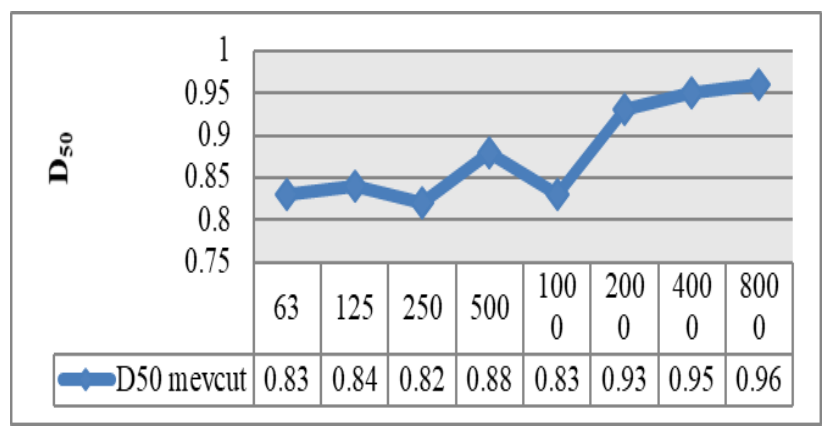

Şekil 9. Oktav band frekanslarda elde edilen D50 değerleri

3.2.4. Ses İletim İndeksi (STI): Derslikte yapılan malzeme değişikliklerinden sonra STI değeri $(0,83)$, anlaşılabilirliğin mükemmel düzeyde olduğu 0,75 ile 1,00 değer aralığında elde edilmiştir (Şekil 10). Bu, mevcut durumdaki STI'dan $(0,63)$ çok daha yüksek değerdedir.

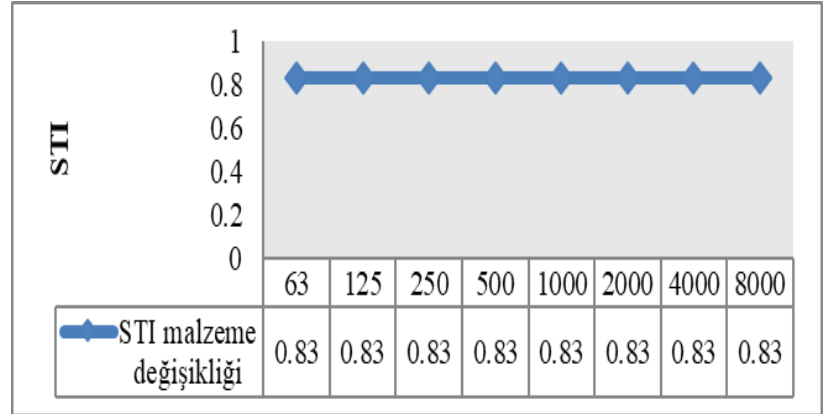

Şekil 10. Oktav band frekanslarda elde edilen STI değerleri

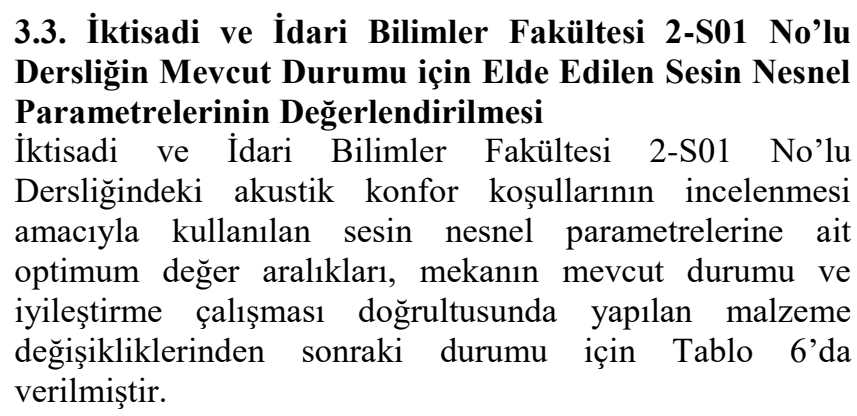

Tablo 6. İktisadi ve İdari Bilimler Fakültesi 2-S01 No’lu Dersliğin mevcut ve malzeme değişikliğinden sonraki durumu için sesin nesnel parametrelerine ait optimum değer aralıkları [14], [15], [16], [17], [18]

\begin{tabular}{|c|c|c|c|c|c|c|}
\hline $\begin{array}{l}\text { Hacim Akustiği } \\
\text { Parametresi }\end{array}$ & $\begin{array}{lrr}\text { İktisadi } \quad \text { ve } & \text { İdari } \\
\text { Bilimler } & \text { Fak. } & \text { 2-S01 } \\
\text { No'lu Derslik } & \end{array}$ & \multicolumn{3}{|c|}{ Optimum (minimum) } & \multicolumn{2}{|c|}{ Optimum (maksimum) } \\
\hline \multirow{2}{*}{ RT } & Mevcut & \multicolumn{3}{|l|}{0,31} & \multicolumn{2}{|l|}{0,51} \\
\hline & Malzeme değişikliği & \multicolumn{3}{|l|}{0,31} & \multicolumn{2}{|l|}{0,51} \\
\hline \multirow{2}{*}{$\mathrm{EDT}_{\text {mid }}$} & Mevcut & \multicolumn{3}{|l|}{0,141} & \multicolumn{2}{|c|}{0,361} \\
\hline & Malzeme değişikliği & \multicolumn{3}{|l|}{0,141} & \multicolumn{2}{|c|}{0,361} \\
\hline $\mathrm{D}_{50}$ & Her iki durum için & \multicolumn{5}{|l|}{$0,50 \leq$} \\
\hline \multirow[t]{2}{*}{ STI } & \multirow[t]{2}{*}{ Her iki durum için } & $0-0.3$ & $\begin{array}{l}0.3- \\
0.45\end{array}$ & $\begin{array}{l}0.45- \\
0.6\end{array}$ & $\begin{array}{l}0.6- \\
0.75\end{array}$ & $0.75-1.0$ \\
\hline & & Kötü & Zayıf & Orta & İyi & Mükemmel \\
\hline
\end{tabular}

3.3.1. Reverberasyon Süresi (RT): Dersliğin mevcut durumu için RT değeri 500 Hz'de (orta frekans bölgesi) 0,65 sn. olarak elde edilmiştir (Şekil 11). Küçük hacimli mekan kapsamında incelenen ve $90 \mathrm{~m}^{3}$ hacme sahip olan dersliğin, orta frekans bölgesindeki optimum RT değeri 0,31 ile 0,51sn. aralığındadır (Tablo 6). Belirtilen değer aralıklarına göre, RT değeri optimum düzeyin üzerinde elde edilmiştir.

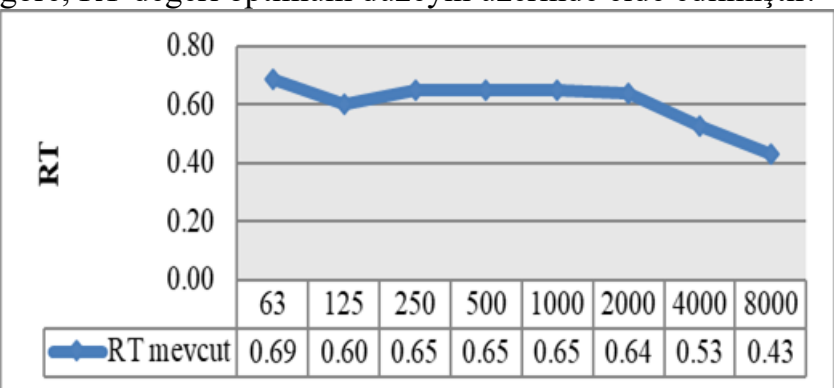

Şekil 11. Oktav band frekanslarda elde edilen RT değerleri

3.3.2. Erken Düșme Süresi (EDT): İktisadi ve İdari Bilimler Fakültesi 2-S01 No'lu Dersliğinin mevcut durumu için EDT değeri, $500 \mathrm{~Hz}$ 'de (orta frekans bölgesi) 0,62 sn. olarak elde edilmiştir (Şekil 12). Optimum EDT değeri ise, orta frekans bölgesinde 0,141 ile 0,361 sn. aralığındadır (Tablo 6). Belirtilen değer aralığına göre, dersliğin mevcut durumu için EDT, optimum düzeyin üzerinde elde edilmiştir.

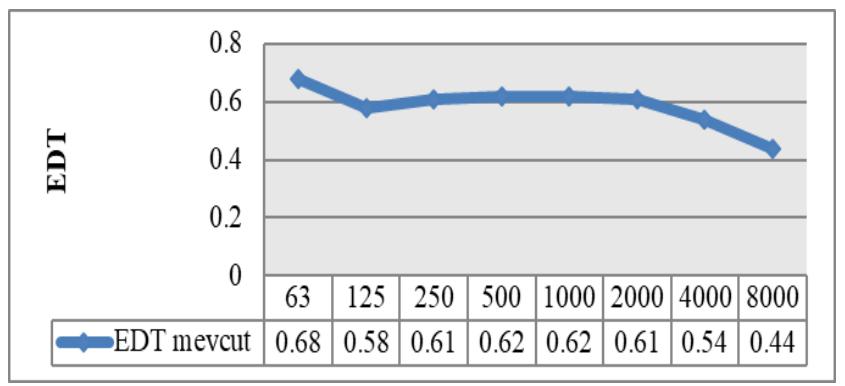

Şekil 12. Oktav band frekanslarda elde edilen EDT değerleri

3.3.3. Konuşmanın Belirginliği ( $\left.\mathbf{D}_{50}\right)$ : Dersliğin mevcut durumu için $\mathrm{D}_{50}$ değeri 0,70 olarak elde edilmiştir (Şekil 13). $\mathrm{Bu}$ değer, $\mathrm{D}_{50}$ optimum alt sinır değerinin üzerindedir. 
Dersliğin mevcut durumu için \%50'nin üzerinde olan $\mathrm{D}_{50}$ parametresine göre, konuşmanın belirginliğinin yeterli düzeyde olduğu belirlenmiştir.

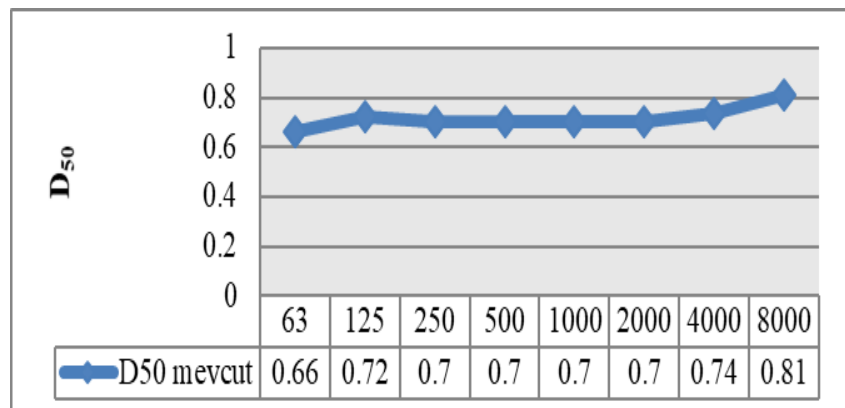

Şekil 13. Oktav band frekanslarda elde edilen D50 değerleri

3.3.4. Ses İletim İndeksi (STI): İktisadi ve İdari Bilimler Fakültesi 2-S01 No'lu Dersliğinin mevcut durumu için STI değeri 0,71 olarak elde edilmiştir (Şekil 14). Elde edilen STI değeri, anlaşılabilirliğin iyi düzeyde olduğu 0,60 ile 0,75 değer aralığındadır (Tablo 6).

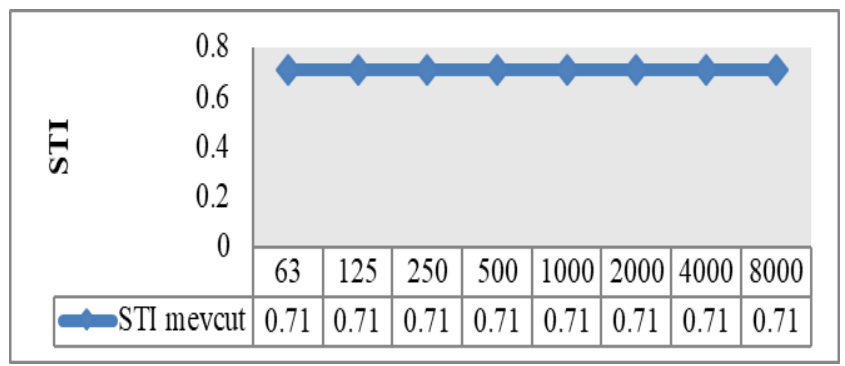

Şekil 14. Oktav band frekanslarda elde edilen STI değerleri

\section{4. İktisadi ve İdari Bilimler Fakültesi 2-S01 No'lu Derslik için İyileştirme Çalışması}

İktisadi ve İdari Bilimler Fakültesi 2-S01 No'lu Dersliği için elde edilen RT ve EDT değerlerini optimum düzeylere getirmek amacıyla, mekan yüzeylerinde bazı malzeme değişiklikleri yapılmıştır. Malzeme değişikliklerinde, alçak frekanslardan yüksek frekanslara doğru ses yutuculukları giderek artış gösteren; zeminde: halı kaplama, tavanda: taş yünü karo levhalar ve duvarlarda: alçı sıva kullanılmıştır. Yan duvarlarda: yerden $90 \mathrm{~cm}$ yukarıdan başlayarak tavan yüzeyine kadar ahşap malzeme kullanılmıştır. Tavanda kullanılan taş yünü asma tavan uygulaması ile uyumlu şekilde sıva altı aydınlatma armatürleri kullanılmıştır (Tablo 4). İyileştirme çalışması kapsamında, 2-S01 No'lu Dersliğin Sketchup 8 programı ile yeniden modellemesi yapılmış ve ODEON V10 programında simülasyon işlemi gerçekleştirilmiştir. Elde edilen sesin nesnel parametre değerlerine göre sonuçlar tekrar değerlendirilmiştir.

3.4.1. Reverberasyon Süresi (RT): İyileştirme çalışması kapsamında, mekanın hacminde herhangi bir değişiklik meydana gelmemiştir. Bu nedenle, optimum RT değerleri mevcut durumdaki gibi 0,31 ile $0,51 \mathrm{sn}$. aralığında kalmıştır (Tablo 6). Bu değer aralığına göre, malzeme değişiklikleri sonucunda RT değeri 0,38 sn. ile optimum düzeyde elde edilmiştir (Şekil 15).

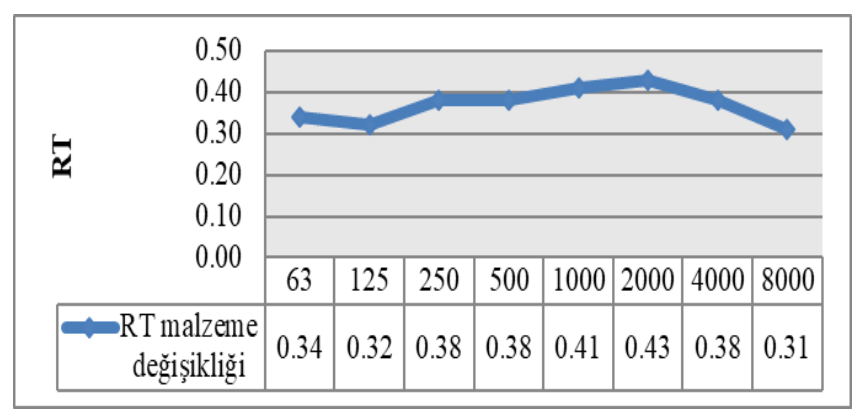

Şekil 15. Oktav band frekanslarda elde edilen RT değerleri

3.4.2. Erken Düşme Süresi (EDT): Derslik için malzeme değişikliklerinden sonraki optimum EDT değeri mevcut durumdaki gibi 0,141 ile 0,361 sn. aralığındadır (Tablo 6). Dersliğin mevcut durumu için optimum değer aralıklarında olmayan EDT değeri (0,62 sn.), malzeme değişikliklerinden sonra $0,31 \mathrm{sn}$. ile optimum düzeyde elde edilmiştir (Şekil 16).

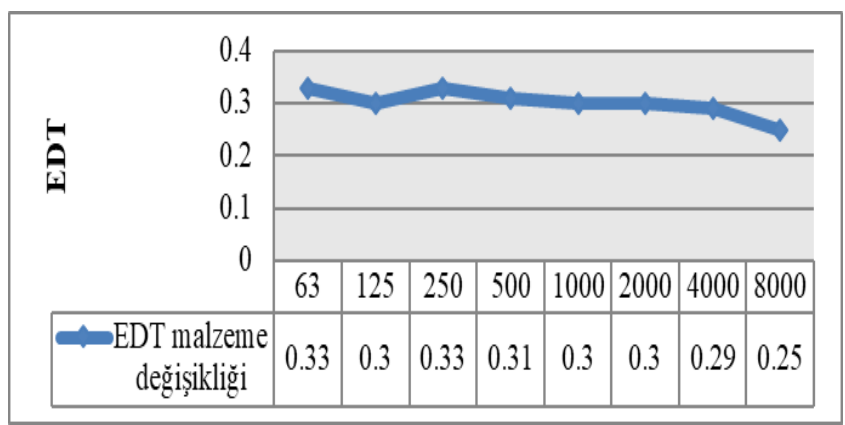

Şekil 16. Oktav band frekanslarda elde edilen EDT değerleri

3.4.3. Konuşmanın Belirginliği (D50): Malzeme değişikliklerinden sonra elde edilen $\mathrm{D}_{50}$ değerinde $(0,90)$, mevcut durumdaki $\mathrm{D}_{50}$ değerine $(0,70)$ göre artış meydana gelmiştir (Şekil 17). Değişiklik sonrasında, derslik için konuşmanın belirginliğinin mevcut duruma göre çok daha iyi olduğu belirlenmiştir.

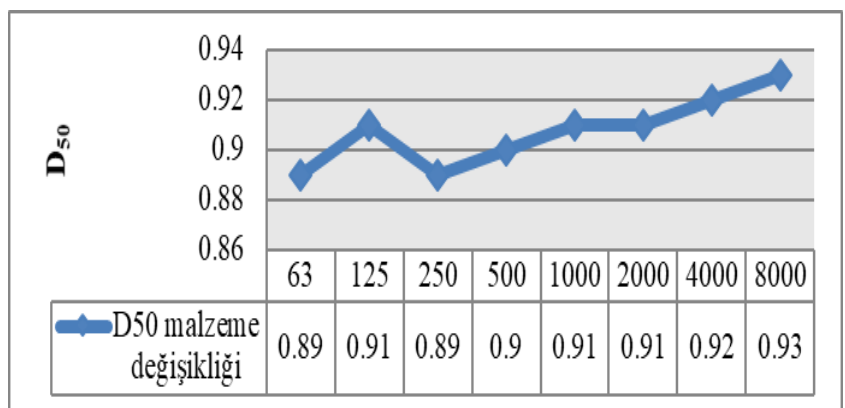

Şekil 17. Oktav band frekanslarda elde edilen D50 değerleri

3.4.4. Ses İletim İndeksi (STI): Derslikte yapılan malzeme değişikliklerinden sonra STI değeri $(0,82)$, anlaşılabilirliğin mükemmel düzeyde olduğu 0,75 ile 1,00 aralığında elde edilmiştir (Şekil 18). Bu, mevcut durumdaki STI değerinden $(0,71)$ daha yüksektir. 


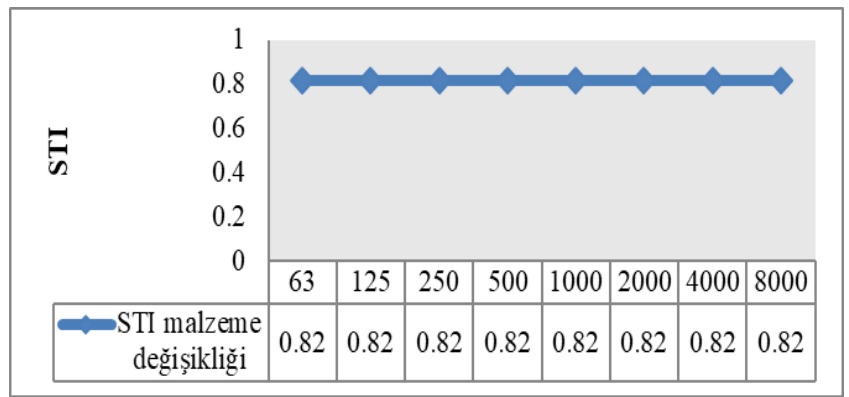

Şekil 18. Oktav band frekanslarda elde edilen STI değerleri

\section{SONUCLAR}

Çalışma kapsamında, KTÜ Peyzaj Mimarlığı'ndaki PMD2 No'lu Derslik ile İktisadi ile İdari Bilimler Fakültesi'ndeki 2-S01 No'lu Derslik akustik açıdan değerlendirilmiş ve iyileştirme çalışması yapılmıştır. Değerlendirme, sesin nesnel parametrelerine bağlı olarak gerçekleştirilmiştir. PMD2 No'lu Derslikte, mevcut durumdaki RT değeri 0,77 sn., EDT değeri 0,91 sn., $\mathrm{D}_{50}$ değeri 0,53 ve STI değeri 0,63 olarak elde edilmiştir. $\mathrm{D}_{50}$ ve STI değerleri optimum aralıkta elde edilirken, RT ve EDT değerleri optimum aralı̆̆ın oldukça üzerinde bulunmuş̧ur. İyileştirme çalışması kapsamında, mekandaki yutuculuk etkisi artırılacak şekilde yüzeylerde malzeme değişiklikleri yapılmıştır. Değişiklik sonrasi; RT değeri 0,38 sn., EDT değeri 0,35 sn., $\mathrm{D}_{50}$ değeri 0,88 ve STI değeri 0,83 olarak elde edilmiştir.

2-S01 No'lu Derslikte, mevcut durumdaki RT değeri 0,65 sn., EDT değeri 0,62 sn., $D_{50}$ değeri 0,70 ve STI değeri 0,71 olarak elde edilmiştir. Bu derslikte de $\mathrm{D}_{50}$ ve STI değerleri optimum aralıkta elde edilirken, RT ve EDT değerleri optimum aralığın üzerinde bulunmuştur. İyileştirme çalışması kapsamında, bu mekandaki yutuculuk etkisi de artırılacak şekilde yüzeylerde malzeme değişiklikleri yapılmıştır. Değişiklik sonrası; RT değeri 0,38 sn., EDT değeri 0,31 sn., $\mathrm{D}_{50}$ değeri 0,90 ve STI değeri 0,82 olarak elde edilmiştir.

Bu durumda, her iki iyileştirme çalışması sonucunda da RT ve EDT değerleri optimum düzeylere getirilirken, optimum düzeylerde olan $\mathrm{D}_{50}$ ve STI değerleri sesin algılanışı açısından daha da iyi düzeylere getirilmiştir.

NOT: Bu çalışma, 2009.120.001.1 No'lu Proje kapsamında KTÜ - BAP Birimi tarafindan desteklenmiştir. Aynı zamanda, KTÜ Mimarlık Anabilim Dalında "Eğitim Yapılarındaki İç Mekanların Bilgisayar Simülasyon Yöntemi ile Akustik Açıdan İncelenmesi, Değerlendirilmesi ve Düzenlenmesi: KTÜ Örneği”" isimli Yüksek Lisans Tezi kapsamında yapılmıştır.

\section{KAYNAKÇA}

[1]. M. Kavraz, Salonların Mimari ve Akustik Açıdan
Tasarım Süreçleri-Gürültü Kontrolü, Ankara: Gece Akademi, 2019.

[2]. R. Abdülrahimov, Salonların Akustiği ve Tasarımı, Trabzon, 1998.

[3] M. Kavraz ,The acoustic characteristics of the Çarşı Mosque in Trabzon, Turkey, Indoor and Built Environment, vol.25 (1), pp. 1-9, June 2014.

[4] K. Eggenschwiler, "Room Acoustic of Classroom with Different Shapes", Euronoise 2006, Tampere, Finland, 2006.

[5] H.Awad, H. Farag, D.Taha, M. Hanafi, Architectural Acoustic in Educational Facilities: An Empirical Study on University Classrooms in Egypt, The Journal of the Acoustical Society of America, vol. 132 (3), 2012.

[6] V. E. Gomez, J.M. Barrigon. Analysis of intelligibility and reverberation time recommendations in educational rooms, Applied Acoustics, vol. 96, pp. 1-10, Septrember 2015.

[7]. Gürel Nihan, "Ilköğretim okullarının akustik açıdan incelenmesi: istanbul'da bir ilköğretim okulu örneği”,, Yüksek lisans tezi, İstanbul Teknik Üniversitesi Fen Bilimleri Enstitüsü, İstanbul, 2007.

[8] Z. Özçetin, F. Demirel, S. Pektaş, M. Eminel, "Eğitim Yapılarında Sürdürülebilir Malzeme ve Akustik Konfor Koşullarının Sağlanmasına Yönelik Bir Çalışma", International Sustainable Buildings Symposium, pp. 314317, Ankara, 2015.

[9] Ö. Y. Karaman, N. B. Üçkaya, "Eğitim mekanlarında akustik konfor: Dokuz Eylül Üniversitesi Mimarlık Fakültesi örneği”, Megaron, vol. 10(4), ss. 503-521, 2015.

[10] M. Bulunuz, N. Bulunuz, J. K. Tuncal, "Akustik iyileştirme yapılmış bir okulda gürültü düzeyinin değerlendirilmesi”, Eğitimde Kuram ve Uygulama, vol. 13(4), ss. 637-658, 2017.

[11] C. L. Christensen, Odeon Room Acoustics Program, Version 10, Denmark: Brüel \& Kjaer, 2009.

[12]

URL: http://www.ptb.de/en/org/1/16/163/datenbank.htm Sound Absorber Materials (Erişim zamanı; Aralık, 15, 2011).

[13] M. Kavraz, "The effect of sound diffusers on the objective parameters of sound: The Multipurpose Hall of Sultanbeyli Cultural Center", American Journal of Scientific Research, Issue 57, pp. 37-46, 2012.

[14] Ş. Sirel, Hacim Akustiğinde Yansışım Süresi, İstanbul: Yapı Fiziği Bilim Dalı Yayınları, IDMMA Basımevi, 1981.

[15] A.C. Gade, "Acoustical Survey of Eleven European Concert Halls" Technical University of Denmark, The Acoustics Laboratory, Report No 44, (1989).

[16] M. Barron, Auditorium Acoustics and Architectural Design. London: E \& FN Spon, 1993.

[17] H. Kuttruff, Room Acoustics, New York: Elsevier Science Publishing, 1991.

[18] M. Long, Architectural Acoustics, New York: Elsevier Inc., 2006. 